\title{
KAJIAN PENGELOLAAN MODAL KERJA PERUSAHAAN
}

\section{Statement of Corporate Employee Management}

\author{
Dr. Sophan Syaiful, S.E., M.M. \\ Jurusan Administrasi Niaga, Universitas Tulang Bawang Lampung \\ E-mail : rachmatandfamily@gmail.com
}

\begin{abstract}
ABSTRAC
Working Capital has an important benefit for a company because it has a close relationship with the daily activities of a company. This working capital must be maintained so as not to overdo it and not lack, it will affect tehadap companies concerned. , in addition to maintaining the company's survival.

The purpose of this study is to analyze the effectiveness of working capital management at CV. Mosal Graphic. The problem studied is the effective or ineffective working capital management and the hypothesis proposed is that CV. Mosal Grafika has not conducted effective working capital management in its operations. To know the effective and effective working capital management is used by using the analysis of financial ratios.

The calculation results obtained based on the analysis of working capital requirements CV. The conclusion that can be taken is that CV. Mosal Grafika has not conducted effective working capital management in its business operation or it can be concluded that the researcher's hypothesis is accepted.
\end{abstract}

Keywords: Working capital

\begin{abstract}
ABSTRAK
Modal Kerja mempunyai manfaat yang penting bagi suatu perusahaan karena mempunyai hubungan yang erat dengan kegiatan sehari-hari suatu perusahaan. Modal kerja ini harus dijaga agar tidak berlebihan dan tidak kekurangan, hal tersebut akan berpengaruh tehadap perusahaan yang bersangkutan. , disamping untuk menjaga kelangsungan hidup perusahaan.

Hasil perhitungan yang didapat berdasarkan analisis kebutuhan modal kerja CV. Mosal Grafika adalah terdapat kelebihan modal kerja dan kelebihan itu meningkat dari tahun ke tahun, analisis sumber dan penggunaan dana menunjukkan bahwa pada setiap periode selalu terdapat selisih dari sumber dana atas penggunaannya,.
\end{abstract}

Berdasarkan analisis kelikuiditan, kemampulabaan, dan keefektifan terlihat bahwa modal kerja CV. Mosal Grafika belum dikelola secara efektif.

Kesimpulan yang dapat diambil adalah bahwa CV. Mosal Grafika belum melakukan pengelolaan modal kerja secara efektif dalam operasi usahanya atau dapat disimpulkan bahwa hipotesis Peneliti diterima.

Kata kunci: Modal kerja 


\section{PENDAHULUAN}

\section{Latar belakang}

Suatu perusahaan didirikan dengan tujuan mempeeroleh laba atau keuntungan, dengan perolehan laba, maka diharapkan peurusahaan dapat mempertahankan kelangsungan hidup nya. Perolehan laba yang merupakan tujuan perusahaan tidak lepas dari keefektifan pengelolaan modal kerja dalam perusahaan, karena terdapat hubungan erat antara modal kerja dan kegiatan se hari hari perusahaan. Pimpinan perusahaan harus menjaga agar besarnya modal kerja tersebut tepat, karena kerja yang terlalu banyak ataupun terlalu sedikit akan membawa perusahaan ke dalam berbagai kesulitan yang apabila tidak diatasi akan menyebabkan kegagalan perusahaan. Ada dua definisi mengenai modal kerja . Pertama, modal kerja adalah selisih lebih angara aktiva lancar dan hutang lancar ; kedua, modal adalah aktiva lancar, ( Amin Widjaya Tunggal, 1995 ; 90-91).

Manfaat dari modal kerja yang cukup dalam suatu perusahaan adalah sebagai berikut :

1. Melindungi perusahaan dari akibat buruk berupa turun nya nilai - nilai aktiva lancar.

2. Memungkinkan perusahaan melunasi kewajiban - kewajiban jangka pendeknya tepat pada waktunya.

3. Memungkinkan perusahaan untuk dapat membeli barang secara tunai sehingga mendapat potongan harga.

4. Menjamin perusahaan memiliki credit standing ( penilaian pihak ketiga, misalnya bank dan para pemberi kredit akan kelayakan peruahaan untuk memelihara kredit ) dan dapat mengatasi peristiwa yang tidak dapat diduga sebelumnya seperti kebakaran, pencurian, dan sebagainya .
5. Memungkinkan perusahaan memiliki persediaan yang cukup untuk melayani perminta pengonsumsi.

6. Memungkinkan perusahaan untuk memberi syarat kredit yang menguntungkan pelanggan.

7. Memungkinkan perusahaan untuk dapat beroprasi dengan efisien karena tidak ada kesulitan dalam memperoleh bahan baku, jasa, dan penawaran yang dibutuhkan.

8. Memungkinkan perusahaan mampu bertahan dalam periode resesi atau depresi. (Djarwanto Ps, 1984; 93).

Tabel 1. Perkembangan Modal kerja CV . Mosal Grafika tahun 1997 2000 (dalam rupiah)

\begin{tabular}{|l|l|l|}
\hline Tahun & Modal kerja & Perubahan (\%) \\
\hline 1997 & $57.753 .500,00$ & - \\
\hline 1998 & $56.195 .250,00$ & $(2,70)$ \\
\hline 1999 & $62.272 .800,00$ & 10,82 \\
\hline 2000 & $66.673 .000,00$ & 7,23 \\
\hline & $\begin{array}{l}\text { Rata - rata } \\
\text { kenaikan }\end{array}$ & 5,12 \\
\hline
\end{tabular}

Sumber : CV Mosal Grafika, 2001

Perkembangan modal kerja CV Mosal Grafika dari tahun 1997 - 2000 memiliki rata - rata kenaikan sebesar $5,12 \%$ seperti terlihat pada tabel 1. Pada tahun 1998 modal kerja CV Mosal Grafika mengalami penurunan sebesar $2,70 \%$, dan pada tahun 1999 terjadi kenaikan sebesar 10,82\%, selanjutnya pada tahun 2000 naik lagi sebesar $7,23 \%$. Hal ini tentunya sedikit banyak berpengaruh pada operasional perusahaan. Di lain pihak tingkat kelikuiditan perusahaan yang diukur dengan rasio lancar tidak begitu menggembirakan karena terdapat penurunan terus menerus dari tahun ke tahun. Hal ini dapat kita lihat pada tabel 2 berikut :

Tabel 2. Keadaan Kelikuiditan CV Mosal Grafika tahun 1997 - 2000 (dalam rupiah). 


\begin{tabular}{|l|l|l|l|}
\hline Tahun & $\begin{array}{l}\text { Aktiva } \\
\text { lancar }\end{array}$ & $\begin{array}{l}\text { Hutang } \\
\text { lancar }\end{array}$ & $\begin{array}{l}\text { Rasi } \\
\text { o } \\
\text { lanca } \\
\text { r }\end{array}$ \\
\hline 1997 & $\begin{array}{l}92.598 .750,0 \\
0\end{array}$ & $\begin{array}{l}34.845 .250, \\
00\end{array}$ & $\begin{array}{l}266 \\
\%\end{array}$ \\
\hline 1998 & $\begin{array}{l}98.845 .650,0 \\
0\end{array}$ & $\begin{array}{l}38.650 .400, \\
00\end{array}$ & $\begin{array}{l}245 \\
\%\end{array}$ \\
\hline 1999 & $\begin{array}{l}108.553 .200, \\
00\end{array}$ & $\begin{array}{l}46.280 .400, \\
00\end{array}$ & $\begin{array}{l}235 \\
\%\end{array}$ \\
\hline 2000 & $\begin{array}{l}123.250 .250, \\
00\end{array}$ & $\begin{array}{l}56.477 .250, \\
00\end{array}$ & $\begin{array}{l}218 \\
\%\end{array}$ \\
\hline
\end{tabular}

Sumber CV Mosal Grafika, 2001

Tingkat kelikuiditan CV Mosal Grafika selama periode 1997 sampai 2000 ditinjau dari rasio lancar mempunyai kecendrungan terus menurun seperti yang terlihat pada tabel 2. Posisi terburuk selama empat tahun terakhir terjadi pada tahun 2002 yaitu sebesar $218 \%$, sedangkan rasio lancar yang tertinggi terjadi tahun1997 yaitu $266 \%$. Keadaan ini dapat dipengaruhi oleh kebijak sanaan pengelolaan modal kerja yang dilakukan perusahaan. Volume penjualan dalam perusahaan dapat pula menunjukan tingkat kefektifan pengelolaan modal kerja dalam suatu perusahaan.

Tabel 3 berikut akan menunjukan perkembangan volume prnjualan CV Mosal Grafika.

Tabel 3. Perkembangan Volume Penjualan CV Mosal Grafika tahun 19972000 (dalam rupiah)

\begin{tabular}{|l|l|l|}
\hline Tahun & $\begin{array}{l}\text { Volume } \\
\text { penjualan }\end{array}$ & $\begin{array}{l}\text { Perubahan } \\
(\%)\end{array}$ \\
\hline 1997 & $458.000 .000,00$ & - \\
\hline 1998 & $440.000 .000,00$ & $(3,93)$ \\
\hline 1999 & $432.500 .000,00$ & $(1,70)$ \\
\hline 2000 & $410.350 .000,00$ & $(5,12)$ \\
\hline
\end{tabular}

Sumber : CV Mosal Grafika

Perkembangan volume penjualan CV Mosal Grafika sejak tahun 1997 - 2000 mengalami rata - rata penurunan sebesar 3,5\% seperti yang dijelaskan tabel 3. Pada tahun 1998 penjuaalan perusahaan mengalami penurunan sebesar 3,93 \% dengan nilai penjualan sebesar Rp440.000.000,00. Pada tahun 1999 penjualan yang dicapai perusahaan mengalami penurunan lagi sebesar $1,70 \%$ dengan penjualan sebesar Rp432.350,00. Kemudian terjadi penurunan lagi pada tahun 2000 dengan persentase sebesar $5,12 \%$. Berdasarkan uraian diatas penulis ingin melakukan evaluasi terhadap keefektifan pengelolaan dan kebutuhan modal kerja pada CV Mosal Grafika, maka judul yang ditemukan adalah : "Kajian Pengelolaan Modal Kerja Perusahaan Studi Kasus pada CV Mosal Grafika Di Bandar Lampung ".

\section{Permasalahan}

Tabel 3. menjelaskan bahwa volume penjualan CV Mosal Grafika mengalami penurunan terus menerus, dan perhitungan yang ada terlihat bahwa rata - rata penurunannya sebesar 3,58 \%. Sedangkan pada tabel 1 dapat dilihat bahwa modal kerja CV Mosal Grafiks meningkat dari tahun ke tahun dengan rata - rata kenaikan sebesar 5,12\%. Tetapi, keadaan kelikuiditan perusahaan ini berdasarkan tingkat kelikuiditan yang diukur dengan rasio lancar memiliki kecendrungan menurun dari tahun ke tahun, kelemahan ini menyebabkan perolehan laba bersih CV Mosal Grafika mengalami penurunan, terlihat pada tabel 4 berikut :

Tabel 4. Perkembangan Modal Kerja dan Laba Bersih CV Mosal Grafika tahun 1997 - 2000 (dalam rupiah)

\begin{tabular}{|l|l|l|l|l|}
\hline Thn & $\begin{array}{l}\text { Modal } \\
\text { Kerja }\end{array}$ & $\begin{array}{l}\text { Pening } \\
\text { katan } \\
(\%)\end{array}$ & $\begin{array}{l}\text { Laba } \\
\text { Bersih }\end{array}$ & $\begin{array}{l}\text { Pening } \\
\text { katan } \\
(\%)\end{array}$ \\
\hline 1997 & $\begin{array}{l}57.753 \\
.500,0 \\
0\end{array}$ & - & $\begin{array}{l}37.453 .5 \\
00,00\end{array}$ & - \\
\hline 1998 & $\begin{array}{l}56.195 \\
.250,0 \\
0\end{array}$ & $(2,70)$ & $\begin{array}{l}33.126 .0 \\
50,00\end{array}$ & $(11,55)$ \\
\hline Thn & $\begin{array}{l}\text { Modal } \\
\text { Kerja }\end{array}$ & $\begin{array}{l}\text { Pening } \\
\text { katan } \\
(\%)\end{array}$ & $\begin{array}{l}\text { Laba } \\
\text { Bersih }\end{array}$ & $\begin{array}{l}\text { Pening } \\
\text { katan } \\
(\%)\end{array}$ \\
\hline 1999 & $\begin{array}{l}62.272 \\
.800,0 \\
0\end{array}$ & 10,82 & $\begin{array}{l}30.212 .5 \\
00,00\end{array}$ & $(8,80)$ \\
\hline 2000 & 66.773 & 7,23 & 29.002 .5 & $(4,00)$ \\
\hline
\end{tabular}




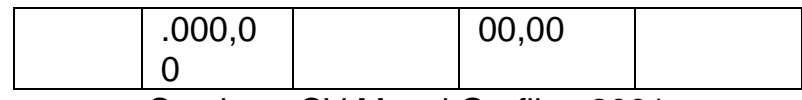

Sumber : CV Mosal Grafika, 2001

\section{METODOLOGI PENELITIAN}

\section{Laporan Keuangan}

Laporan keuangan merupakan suatu hasil akhir dari proses akuntansi yang dapat di gunakan sebagai alat komunikasi antara pihak intern perusahaan dengan pihak ekstern yang berkepentingan terhadap data atau kegiatan perusahaan. Laporan keuangan menyatakan jumlah kekayaan, kewajiban - kewajiban dan modal perusahaan pada suatu saat, serta hasil kegiatan perusahaan pada suatu periode. Di samping itu laporan keuangan juga mencerminkan kebijaksanaan pimpinan suatu perusahaan dalam mengurus perusahaannya, sehingga dengan demikian potensi dan kondisi perusahaan dapat di ketahui.

Pihak - pihak yang berkepentingan terhadap laporan keuangan perusahaan antara lain :

\section{a. Para pemilik perusahaan}

Berdasarkan laporan keuangan, pemilik dapat menilai sukses tidak nya manajemen dalam mengelola kegiatan usaha didalam perusahaan, di mana hal ini diukur dari laba yang diperoleh. Kestabilan dan kesinambungan perusahaan juga harus diperhatikan dan hal ini tergantung dari keefesienan kerja pengelola perusahaan.

\section{b. Pengelola perusahaan}

Laporan keuangan bagi pengelola perusahaan merupakan alat untuk pertanggung jawaban kepada pemilik perusahaan atas kepercayaan yang diberikan. Melalui analisisis laporan keuangan pengelola perusahaan dapat menilai apakah operasi perusahaan berjalan dengan efisien atau tidak.

c. Para penanam modal, bankir, dan pemberikredit lain
Para penanam modal, bankir maupun para pemberi kredit lainnya sangat berkepentingan atas laporan keuangan perusahaan karena mereka menanamkan modalnya dalam perusahaan.

\section{d. Pemerintah}

Pemerintah memerlukan laporan keuangan karena dengan menganalisa laporan keuangan dapat ditentukan besarnya pajak yang dikenakan pemerintah terhadap perusahaan tersebut laporan keuangan juga merupakan input bagi pemerintah untuk mengevaluasi kebijaksanaan dan peraturan yang dikeleluarkan oleh pemerintah.

\section{HASIL DAN PEMBAHASAN}

Berdasarkan hasil perhitungan, pengelolaan modal kerja yang dilakukan CV Mosal Grafika belum dikatakan efektif. Hal ini ditunjang dengan fakta bahwa terdapat kecenderungan penurunan pada aspek aspek yang berkaitan erat dengan modal kerja, yaitu terdapatnya penurunan likuiditas perusahaan, turunnya kemampulabaan dan juga terlihat adanya penurunan pada volume penjualan perusahaan dengan kondisi seperti ini maka hipotesis peneliti yaitu bahwa " CV Mosal Grafika belum melakukan pengelolaan modal kerja secara efektif dalam operasi usahanya “" telah dapat dibuktikan.

Analisis kebutuhan modal kerja

Perhitungan kebutuhan modal kerja menggunakan laporan keuangan CV Mosal Grafika yang berupa neraca dan laporan laba rugi tahun 1997 - 2000. Perhitungan kebutuhan modal kerja yang dibutuhkan CV Mosal Grafika selama periode tahun 1997 2000 menggunakan 2 periode tahun yang berurutan.

\section{Tabel 5. Tingkat perputaran elemen modal kerja pada aktiva lancar tahun 1998.}

\begin{tabular}{|l|l|}
\hline Elemen modal kerja & Tingkat perputaran \\
\hline Kas & $30,31 \mathrm{kali}$ \\
\hline Piutang dagang & $10,68 \mathrm{kali}$ \\
\hline
\end{tabular}




\begin{tabular}{|l|l|}
\hline Piutang lain - lain & 76,19 kali \\
\hline Persediaan BB & 12,28 kali \\
\hline
\end{tabular}

Sumber : CV Mosal Grafik, 2001

Tingkat perputaran kas adalah sebanyak 40,31 kali deperti ditunjukan tabel 5, sedangkan tingkat piutang dagang adalah sebanyak 10,68 kali, piutang lain - lain mempunyai tingkat perputaran sebanyak 76,19 kali, sedangakan persediaan BB mempunyai tingkat perputaran sebanyak 76,19 kali, sedangkan BB mempunyai tingkat perputaran sebanyak 12,28 kali.

\section{Analisis Hasil Usaha atau Analisis Kemampuan}

Analisis ini digunakan untuk mengukur kemampuan perusahaan untuk menghasilkan laba atau keuntungan. Dalam analisa ini digunakan rasio laba terhadap penjualan, dan tingkat laba dari aktiva. Keadaan kemampulabaan CV Mosal Grafika dapat dilihat pada tabel 6 berikut :

Tabel 6. Rasio hasil usaha atau kemampulabaan CV Mosal Grafika tahun 1997 - 2000

\begin{tabular}{|l|l|c|}
\hline Tahun & $\begin{array}{l}\text { Rasio laba } \\
\text { terhadap } \\
\text { penjualan }\end{array}$ & $\begin{array}{l}\text { Tingkat laba } \\
\text { dari aktiva }\end{array}$ \\
\hline 1997 & $8,18 \%$ & 11,13 \\
\hline 1998 & $7,53 \%$ & $9,78 \%$ \\
\hline 1999 & $6,99 \%$ & $8,50 \%$ \\
\hline 2000 & $7,07 \%$ & $7,65 \%$ \\
\hline \multicolumn{2}{|c|}{ Sumber $:$ CV Mosal Grsfika, 2001 } \\
\hline
\end{tabular}

Rasio hasil usaha atau kemampuan CV Mosal Grafika berdasarkan rasio laba terhadap penjualan dari tahun 1997 sampai dengan tahun 1999 mengalami penurunan seperti terlihat pada tabel 6 yaitu masing masing, 8,18\% pada tahun 1997, menjadi $7,53 \%$ pada tahun 1998, lalu mengalami penurunan lagi di tahun 1999 sebesar 6,99\%. Pada tahun 2000 rasio laba terhadap penjualan CV Mosal Grafika mengalami kenaikan sedikit yaitu sebesar $7,07 \%$.

\section{Analisis rasio keefesienan atau rasio}

\section{Keaktifan.}

Tujuan pengguna analisis keefesienan adalah untukmengetahui bagaimana keaktifan perusahaan dalam hal ini CV Mosal Grafika dalam penggunaan dana di perusahaannya yaitu dengan memperhitungkan :

\section{Tingkat perputaran aktiva}

Rasio ini dihitung dengan embandingkan penjualan bersih dengan jumlah aktiva. Adapun tingkat perputaran aktiva CV Mosal Grafika tahun 1997 - 2000 dapat dilihat pada tabel 7 berikut :

\section{Tabel 7. Tingkat perputaran aktiva CV Mosal Grafika tahun 1997 - 2000}

\begin{tabular}{|l|l|l|l|}
\hline Thn & $\begin{array}{l}\text { Penjualan } \\
\text { bersih } \\
\text { (Rp) }\end{array}$ & $\begin{array}{l}\text { Aktiva } \\
\text { (Rp) }\end{array}$ & $\begin{array}{l}\text { Tingkat } \\
\text { perputar } \\
\text { an aktiva }\end{array}$ \\
\hline 1997 & $458.000 .000,-$ & 336.548 .750 & 1,36 kali \\
\hline 1998 & $440.000 .000,-$ & 338.645 .025 & 1,30 kali \\
\hline 1999 & $432.500 .000,-$ & 355.402 .700 & 1,22 kali \\
\hline 2000 & $410.350 .000,-$ & 379.279 .750 & 1,08 kali \\
\hline \multicolumn{3}{|c|}{ Sumber : CV Mosal Grafika, 2001 } \\
\hline
\end{tabular}

2. Tingkat perputaran piutang

Rasio ini dihitung dengan cara membandingkan penjualan bersih perusahaan dengan piutang perusahaan. Keadaan tingkat perputaran piutang CV Mosal Grafika tahun 1997 - 2000 dapat dilihat pada tabel berikut :

Tabel 8. Tingkat perputaran piutang CV Mosal Grafika tahun $1997-2000$

\begin{tabular}{|c|c|c|c|}
\hline Thn & $\begin{array}{l}\text { Penjualan } \\
\text { bersih }\end{array}$ & $\begin{array}{l}\text { Piutang } \\
\text { dagang }\end{array}$ & $\begin{array}{l}\text { Tingkat } \\
\text { perputar } \\
\text { an } \\
\text { piutang }\end{array}$ \\
\hline 1997 & $\begin{array}{l}\text { Rp } 458.000 .00 \\
0,00\end{array}$ & $\begin{array}{l}\text { Rp39.971.200, } \\
00\end{array}$ & 11,46 kali \\
\hline 1998 & $\begin{array}{l}\text { Rp } 440.000 .00 \\
0,00\end{array}$ & $\begin{array}{l}\text { Rp42.420.250, } \\
00\end{array}$ & 10,37 kali \\
\hline
\end{tabular}




\begin{tabular}{|l|l|l|l|}
\hline 1999 & $\begin{array}{l}\text { Rp432.500.00 } \\
0,00\end{array}$ & $\begin{array}{l}\text { Rp42.250.000, } \\
00\end{array}$ & 9,56 kali \\
\hline 2000 & $\begin{array}{l}\text { Rp410.350.00 } \\
0,00\end{array}$ & $\begin{array}{l}\text { Rp50.650.000, } \\
00\end{array}$ & 8, 10 kali \\
\hline
\end{tabular}

Sumber : CV Mosal Grafika, 2001

\section{Tingkat perputaran modal kerja}

Rasio ini dihitung dengan membandingkan penjualan bersih dengan jumlah modal keja yang ada pada CV Mosal Grafika. Adapun tingkat perputaran modal kerja tersebut dapat dilihat pada tabel berikut :

Tabel 9. Tingkat perputaran modal kerja CV Mosal Grafika tahun 1997 - 2000

\begin{tabular}{|l|l|l|l|}
\hline Thn & $\begin{array}{l}\text { Penjualan } \\
\text { bersih }\end{array}$ & $\begin{array}{l}\text { Modal } \\
\text { kerja }\end{array}$ & $\begin{array}{l}\text { Tigkat } \\
\text { perputar } \\
\text { an Kerja }\end{array}$ \\
\hline 1997 & $458.000 .000,-$ & 57.753 .500 & 7,93 kali \\
\hline 1998 & $440.000 .000,-$ & 56.195 .250 & 7,83 kali \\
\hline 1999 & $432.500 .000,-$ & 62.272 .800 & 6,95 kali \\
\hline 2000 & $410.350 .000,-$ & 66.773 .000 & 6,15 kali \\
\hline
\end{tabular}

Rata - rata tingkat perputaran modal kerja CV Mosal Grafika adalah 7,2 kali yang dapat kita lihat pada tabel 9, berarti bahwa dana yang tertanam dalam modal kerja berputar rata - rata 7,2 kali dalam setahunnya. Tingkat perputaran modal kerja CV Mosal Grafika dari tahun 1997 - 2000 terus menurun atau dengan kata lain semakin lambat yaitu dari 7,93 kali ditahun 1997 turun menjadi 7,83 di tahun 1998, kemudian turun lagi sebesar 6,95 ditahun 1999, dan pada akhirnya di tahun 2000 menurun lagi menjadi sebesar 6,15 kali. Hal ini disebabkan antara lain semakin rendahnya tingkat peputaran persediaan dan piutang dagang yang ada dalam perusahaan. Hal ini juga berkaitan dengan pengelolaan modal kerja yang belum efektif pada CV Mosal Grafika.

\section{KESIMPULAN DAN SARAN}

\section{KESIMPULAN}

Berdasarkan perhitungan dan pembahasan pada bab terdahulu maka simpulan yang didapat adalah bahwa hipotesis peneliti yaitu “ CV Mosal Grafika belum melakukan pengelolaan modal kerja secara efektif dalam operasi usahanya " , telah dapat dibuktikan. Pembuktian tersebut dapat dilihat dari penjelasan - penjelasan sebagai berikut :

Hasil analisis modal kerja CV Mosal Grafika menunjukan adanya ketidakefektifan dalam pengelolaan modal kerja dalam perusahaanyang menimbulkan ketidakefesienan modal kerja, dimana selama periode tahun 1997 - 2000 CV Mosal Grafika selalu mengalami kelebihan modal kerja yang meningkat pada tiap tahunnya.

Sumber - sumber modal kerja berasal dari bertambahnya laba ditahan dan bertambahnya akumulasi penyusutan aktiva tetap perusahaan. Sumber - sumber terbesar terdapat pada periode $1999-2000$ yaitu penambahan laba ditahan sebesar Rp14.890.200,00.

Berdasarkan analisis rasio keefektifan atau rasio keaktifan, tingkat perputaran aktiva tingkat perputaran piutang dan tingkat perputaran modal kerja CV Mosal Grafika tidaklah menggembirakan karena tingkat perputarannya semakin rendah atau dengan kata lain tingkat perputaran tersebut semakin lambat, yaitu dari tingkat perputaran sebsar 1,36 kali di tahun 1997 sampai mencapai 1,8 kali di tahun 2000 .

Dan untuk tingkat peputaran modal kerja dari tahun 1997 sebesar 7,93 kali terjadi penurunan terus sehingga menjadi 6,15 kali di tahun 2000. Dengan adanya penurunan penurunan yang terjadi dan tingkat - tingkat perputaran yang mempunyai kecendrungan melambat maka hal ini menunjukan pada kita bahwa pengelolaan modal kerja yang dilakukan oleh CV Mosal Grafika dalam operasi usahanya belum efektif.

\section{SARAN}

Untuk mengatasi ketidak efektifan pengelolaan modal kerja perusahaan yang menimbulkan penurunan - penurunan dalam perusahaan antara yaitu antara lainpenurunan hasil usaha atau kemampulabaan, penurunan kelikuiditan perusahaan, sebaiknya CV Mosal Grafika 
lebih memperhatikan dan menitik beratkan perhatian pada pengelolaan modal kerja yang seefektif mungkin. Perusahaan peru mengadakan perencanaan yang matang dan teliti pengalokasian dana dalam perusahaan sehingga dana perusahaan dapat digunakan seefektif dan seefesien mungkin sesuai dengan proporsinya

Bila dilihat dari rasio keefesienan, dengan semakin lambatnya atau rendahnya tingkat perputaran aktiva, piutang dan modal kerja mengakibatkan adanya dana yang tidak produktif dalam perusahaa. Keadaan ini harus segera diatasi karena banyaknya dana tertanam yang tidak produktif akan menimbulkan kesulitan bagi perusahaa. Untuk itu sebaiknya CV Mosal Grafika memperbaiki kebijaksanaan dalam investasi modal kerja perusahaan dalam rangka meningkatkan rasio keefesienan atau rasio keaktifannya. Perusahaan juga sebaiknya memperbaiki kebijaksanaan kreditnyaatau kebijaksanaan piutang agar lebih ketat sehingga tidak menimbulkan kesulitan pada perusahaan.

Keadaan hasil usaha atau kemampulabaan CV Mosal Grafika dapat ditingkatkan dengan jalan memperbesar marjin laba yaitu dengan cara meningkatkan volume penjualan perusahaan dan menekan biaya usaha sebesar - besarnya atau melakuakan pengurangan pendapatan dari penjualan sampai tingkat tertentu sehingga terdapat pengurangan biaya operasi seefesien mungkin.

\section{DAFTAR PUSTAKA}

[1] Amin, Widjaja Tunggal, 1995. Dasardasar Analisis Laporan Keuangan. Penerbit Rineaka Cipta, Jakarta.

[2] Riyanto, Bambang. 1984. Dasar-Dasar Pembelajaran Perusahaan. Yayasan Penerbit Gajah Mada, Yogyakarta.

[3] Djarwanto, Ps 1984. Pokok-pokok Analisa Laporan Keuangan. Penerbit BPFE, Yogyakarta.
[4] Faisal, Afif- Supandi, Utjup. 1985. Manajemen Modal Kerja. Penerbit Remaja Karya CV, Bandung

[5] Harnanto. 1985. Analisa Laporan Keuangan. Penerbit BPFE, Yogyakarta.

[6] S, Munawir. 1986. Analisa Laporan Keuangan. Penerbit Liberty, Yogyakarta.

[7] Suad, Husnan. 1989. Dasar-dasar Manajemen Keuangan. Edisi Kedua, Penerbit Liberty, Yogyakarta. 